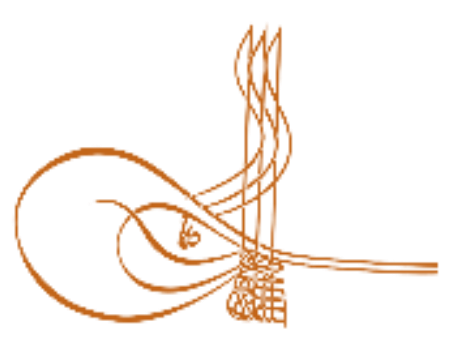

www.turkishstudies.net/turkishstudies
Turkish Studies

eISSN: $1308-2140$

Research Article / Araştırma Makalesi

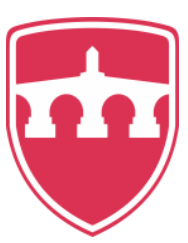

INTERNATIONAL

BALKAN

UNIVERSITY

Sponsored by IBU

\title{
Sporcu Öğrencilerde Optimal Performans Duygu Durumun Araştırılması*
}

\author{
Investigation of Optimal Performance Emotional Status in Sports Students
}

\author{
Faruk Yamaner $^{* *}$ - Ertuğrul Çıplak ${ }^{* * *}$ - Osman İmamoğlu ${ }^{* * * *}$
}

\begin{abstract}
The aim of this study is to investigate the Optimal performance Emotion situation in students receiving Sports Education at the University. "Continuous Optimal Performance Emotional Status Scale-2 (SOPDDÖ-2)" is a measure of the overall performance of the optimal performance emotional state on the individual participating in the activity and aims to evaluate the frequency of physical performance and optimal performance experience in participation in sports. The adaptation study of the scale into Turkish was done by Aşçı et al. (2007). 23.00 SPSS package program was used in the analysis of the data. The data obtained as a result of the scale were calculated in accordance with the scoring directive. While evaluating the data, the compatibility of normal distribution with the "Kolmogorov Smirnov Test" was investigated and it was determined that all data fit the normal distribution. 190 university students participated in the study. Ttest was used for statistical procedures. In this study, no significant difference was found in the comparison of the sub-dimensions of optimal performance (Dispositional Flow) mood state scales according to gender ( $p>0.05$ ). Again, there was no difference in the comparison of the sub-dimensions of optimal performance mood status scale according to team and individual sports ( $p>0.05$ ). In terms of the optimal performance, the Dispositional Flow sub-dimension scores are almost all close to 20 points. Therefore, the optimal performance of the participants can be considered as good. It can be said that the performance emotions of men and women, team and individual athletes are similar. Conclusion: Optimal performance emotional state of students receiving sports education at the university can be accepted as good. Optimal performance mood scores were found to be similar in terms of gender, team and individual sports. It should be examined in
\end{abstract}

\footnotetext{
* Çalışmada kullanılan veriler 2019 yılına aittir.

*** Prof. Dr., Hitit Üniversitesi, Fakülte, Spor Bilimleri Fakültesi, Antrenörlük Eğitimi Bölümü

Prof. Dr., Hitit University, Faculty, Faculty of Sport Sciences, Department of Coaching Education

ORCID 0000-0002-2302-8650

yamanerf@ hotmail.com

**** Dr.Öğr. Üyesi, Zonguldak Bülent Ecevit Üniversitesi, Beden Eğitimi ve Spor Yüksekokulu, Beden Eğitimi ve Spor Eğitimi Bölümü

Assst Prof. Dr., Zonguldak Bülent Ecevit University, School of Physical Education and Sports, Department of Physical Education and Sports Education

ORCID 0000-0001-5338-3349

mertugrul.ciplak@beun.edu.tr

***** Prof. Dr., Ondokus Mayıs Üniversitesi Yaşar Doğu Spor Bilimleri Fakültesi, Spor Yöneticiliği Bölümü

Professor Prof., Ondokus Mayls University Yaşar Eastern Faculty of Sports Sciences, Department of Sports Management ORCID 0000-0001-6671-6042

osmani55@hotmail.com

Cite as/ Atıf: Yamaner, F., Çıplak E., İmamoğlu, O. (2020). Sporcu öğrencilerde optimal performans duygu durumun araştırılmas1, Turkish Studies, 15(2), 1515-1522. https://dx.doi.org/10.29228/TurkishStudies.41771

Received/Geliş: 14 February/Şubat 2020

Checked by plagiarism software

Accepted/Kabul: 25 April/Nisan 2020

Published/Yayın: 30 April/Nisan 2020

Copyright (C) INTAC LTD, Turkey

CC BY-NC 4.0
} 
which sub-dimensions the optimal performance emotional state differs in different age categories and in different groups (elite athletes, disabled athletes).

Structured Abstract: While the first studies on optimal performance emotional state included physical activities (using computer, dancing, etc.) in our daily life, later studies on optimal performance experience in sports environment started to take place. If the athlete has high performance and high skill level, if the task is difficult, he experiences the optimal performance experience and reaches the optimal performance mood level (Altıntaş et al., 2010). It has been revealed that determining the optimal performance emotional state increases the student's participation in the activity, helps to ensure continuity in participation in the activity, increases the perception of competence and helps the perception of the course environment (atmosphere) as a task (Ada et al., 2012). The relationship between optimal performance emotional state and motivation, goal orientation, motivational climate, perceived competence, anxiety), free will, self-perception and other psychological skills (goal setting, imagination, positive thinking, relaxation) were examined. In general, it has been determined that there is a positive relationship between intrinsic motivation, ego orientation and performance climate and optimal performance mood, and those with high perceived competence have high optimal performance emotions (Altıntaş et al., 2010).

The Ondokuz Mayıs University Yaşar Eastern Faculty of Sport Sciences Continuous Optimal Performance Emotion Scale, which consisted of 190 students, 108 males and 82 females, was evaluated.

23.00 SPSS package program was used in the analysis of the data. The data obtained as a result of the scale were calculated in accordance with the scoring directive. While evaluating the data, the compatibility of normal distribution with the "Kolmogorov Smirnov Test" was investigated and it was determined that all data fit the normal distribution. T-test was used in comparisons.

The average age of the students who attended the study was 22.13 years, their height was $171.90 \mathrm{~cm}$ and their body weight was $68.89 \mathrm{~kg}$.

Based on the idea that optimizing all nine components (Task difficulty / Skill balance, Action awareness combination, Clear objectives, Specific feedback, Focus on task, Sense of control, Self Awareness reduction, Time transformation and Achieving experience) during a single activity can create optimal arousal state. The optimal performance mood theory emphasizes that performance can be positively affected (Yildiz et al., 2015). Yildiz et al. (2015) found that optimal performance emotional states differed by gender factor. As a result of this difference, it is stated that male athletes have higher average scores than female athletes. The findings of the research conducted by Ersöz (2011) are similar. In the study conducted by Bayköse (2014), there is a difference only in the Dimension of Self Awareness Reduction sub-dimension, which is the sub-dimension of optimal performance emotional state. As a result of their study, Sharp et al. (2007) stated that optimal performance emotional state does not vary according to physical activity type and gender. Murcia et al. (2008) evaluated the optimal performance moods of athletes in different branches by gender, and revealed that there was no difference between the performance moods of male and female athletes. The results obtained by Koehn (2007) are also stated to be no gender difference. In this study, no significant difference was found in the sub-dimensions when comparing the sub-dimensions of optimal performance and mood scale by gender ( $p>0.05)$. It can be said that the performance emotional states of male and female student athletes are similar. Again, the highest 20 points can be obtained for each sub-dimension from the scale. Looking at the averages in this study, all sub-dimension mean scores are close to 20 points. For this reason, the optimal performance emotional states of the students participating in the study can be accepted as good. Optimal performance emotional state of students receiving sports education at the university can be accepted as good. Optimal performance mood scores were found to be similar in terms of gender, team and individual sports. It should be examined in which sub-dimensions the optimal performance emotional state differs in different age categories and different groups (elite athletes, disabled athletes)

Keywords: Athlete, Emotion, Optimal performance

Öz: Bu çalışmanın amacı Üniversite'de Spor Eğitimi alan öğrencilerde Optimal performans Duygu durumun araştırılmasıdır. Araştırmaya 190 üniversite de spor eğitimi alan öğrencisi katılmıştır. "Sürekli Optimal Performans Duygu Durum Ölçeği-2 (SOPDDÖ-2)" optimal performans duygu durumunun aktiviteye katılan birey üzerindeki genel durumunun bir ölçümüdür ve fiziksel aktivite ile spora katılımdaki optimal performans deneyim sıklığını değerlendirmeyi amaçlar. Ölçek sonucu elde edilen veriler puanlama 
yönergesine uygun olarak hesaplanmıştır. Veriler değerlendirilirken "Kolmogorov Smirnov Testi” ile normal dağılıma uygunluğu araştırılmış ve tüm verilerin normal dağılıma uyduğu tespit edilmiştir. İstatistiksel işlemlerde t- testi kullanılmıştır. Bu çalışmada cinsiyete göre optimal performans duygu durum ölçeği alt boyutları karşılaştırılmasında anlamlı bir farklılık bulunmamıştır ( $p>0,05)$. Yine takım ve ferdi spor yapmaya göre optimal performans duygu durum ölçeği alt boyutları karşılaştırılmasında bir farklılık bulunmamıştır ( $>>0,05)$. Optimal performans duygu durum ölçek alt boyut puanlarına bakıldığında hemen hepsi 20 puana yakındır. Bu nedenle çalışmaya katılanların optimal performans duygu durumları iyi olarak kabul edilebilir. Kadın ve erkek öğrencilerin, takım ve ferdi sporcuların performans duygu durumlarının benzer olduğu söylenebilir. Öğrencilerin Optimal performans duygu durumu iyi olarak kabul edilebilir. Optimal performans duygu durumu puanları cinsiyete, takım ve ferdi spor yapma durumuna göre benzer olduğu tespit edilmiştir. Farklı yaş kategorilerinde ve farklı gruplarda ptimal performans duygu durumunun hangi alt boyutlarda farklılaştı̆̆ incelenmelidir.

Anahtar Kelimeler: Sporcu öğrenci, Duygu durumu, Optimal performans.

\section{Giriş}

Optimal Performans Duygu Durumu spor ve fiziksel aktivite ortamında, bireylerin fiziksel aktivite sırasında sergiledikleri becerileri ile o anda algılanan durum, gereklilikler veya mücadele arasında kurdukları denge sonucunda oluşan optimal zihinsel durumdur (Aşçı ve ark., 2007; Csikszentmihalyi,1990). Kişinin aktiviteden aldığı haz, aktivitenin kişinin beceri düzeyiyle uygunluğu ya da uygunsuzluğu karşısında yaşadığı duygular ve bunların sonucunda kişinin en uygun (optimal) performans deneyimini yaşamış olup olmamasının, bireyin aktiviteyi sürdürmesini ya da aktiviteye tekrar katılımını etkileyebildiği belirtilmektedir (Deci ve Ryan, 1985). Optimal performans duygu durumumun tanımına bakıldığında, bireyin yapmış olduğu görevin içinde kaybolmas1, görev üzerinde bilişsel yeterliği ve kontrolü olduğunu hissetmesi ve yaptığ aktiviteden almış olduğu yüksek derecede içsel haz ve zevk olarak tanımlandığı görülür (Moneta, 2004).

Optimal performans duygu durumu ile ilgili yapılan ilk çalışmalarda günlük hayatımızda yer alan fiziksel aktiviteler (bilgisayar kullanmak, dans etmek vb.) yer alırken, daha sonraları spor ortamında optimal performans deneyiminin incelendiği çalışmalar yer almaya başlamıştır. Sporcu yüksek performans ve yüksek beceri düzeyine sahip ise verilen görevin zor olması durumunda, optimal performans deneyimini yaşamakta ve optimal performans duygu durum düzeyine ulaşmaktadır (Altıntaş ve ark.,2010). Optimal performans duygu durumunu belirlemenin, öğrencinin aktiviteye katılımını arttırdığını, aktiviteye katılımda süreklilik sağlanmasına yardımcı olduğunu, yeterlik algısını arttırdığını ve ders ortamının (atmosferinin) görev içerikli olarak algılanmasına da yardımcı olduğunu ortaya koymuştur (Ada ve ark., 2012). Optimal performans duygu durumu ile güdülenme, hedef yönelimi, güdüsel iklim, algılanan yeterlik, kayg1), hür irade, benlik algisı ve diğer psikolojik beceriler (hedef belirleme, imgeleme, pozitif düşünme, gevşeme) arasındaki ilişki irdelenmiştir. Genel olarak içsel güdülenme, ego yönelimi ve performans iklimi ile optimal performans duygu durumu arasında pozitif ilişki olduğu, algılanan yeterliği yüksek olanların optimal performans duygu durumlarının da yüksek olduğu tespit edilmiştir(Altıntaş ve ark.,2010).Optimal performans duygu durumunu konu alan çalışmalar, pozitif duygu durumları, beceri gelişimi, egzersiz davranışı, performans arttırma ve yaşam doyumu gibi kavramlar ile ilişkili olması nedeniyle büyük önem taşımaktadır (Asakawa,2004). Birey yüksek beceri düzeyine sahip ise verilen görevin zor olması durumunda, optimal performans deneyimini yaşamakta ve optimal performans duygu durum düzeyine ulaşmaktadır. Başka bir deyişle, optimal performans duygu durumu, bireyin yüksek düzeyde mücadele ve zorluk gerektiren görevleri başarabilecek ve bu görevler üzerinde kontrol sağlayabilecek beceriye sahip olması durumunda oluşmaktadır (Moneta, 2004). Performans kalitesine katkıda bulanabilecek psikolojik süreçlerin ne olabileceğini anlamak için optimal performans ile ilişkili psikolojik yapıları incelemek araştırmacıların ilgi odağı olmuştur (Yıldız ve ark.,2015). Optimal performans duygu durumu spor ve egzersiz ortamında yaşanan optimal performans deneyimi ile oluşan zihinsel ve psikolojik durumu yansıtmaktadır 
(Jackson ve ark., 1998). Antrenman ya da maç esnasında sporcu farklı hisler yaşayabilmektedir. Sporun yapıldığı ortamda olan farklı durumlar, sporcunun heyecan, stres ve kayg1 gibi duyguları yaşamasına zemin hazırlayabilir. Bu nedenden dolayı sporcunun performansı duygu durumlarına bağlı olarak olumsuz etkilenebilir. Sporcunun teknik ve taktik kapasitesinin dişında o an içinde bulunduğu psikolojik durum da performansın kalitesini belirleyen bir unsurdur. Performans1 etkileyen bir diğer unsur da optimal performans duygu durumudur (Seleciler,2019).

Bu çalışmada Üniversite'de Spor Eğitimi alan Öğrencilerde Optimal performans Duygu durumun cinsiyete ve spor durumuna göre değişiminin araştırılması amaçlanmıştır.

\section{Metot}

Ondokuz Mayıs Üniversitesi Yaşar Doğu Spor Bilimleri Fakültesinde Üniversite eğitimi alan 108 erkek ve 82 kadın olmak üzere toplam 190 öğrencinin doldurduğu Sürekli Optimal Performans Duygu Durum Ölçeği değerlendirilmiştir.

Veri Toplama Aracı: "Sürekli Optimal Performans Duygu Durum Ölçeği-2 (SOPDDÖ2)" optimal performans duygu durumunun aktiviteye katılan birey üzerindeki genel durumunun bir ölçümüdür ve fiziksel aktivite ile spora katılımdaki optimal performans deneyim sıklı̆̆ını değerlendirmeyi amaçlar. Ölçeğin, Türkçeye uyarlama çalışması Aşçı ve ark.,(2007) tarafindan yapılmıştır. Ölçek 36 madde ve 9 alt ölçekten oluşmaktadır. Bu alt ölçekler Görev Zorluğu/ Beceri Dengesi (1,10,19 ve 28. maddeler), Eylem-Farkındalık Birleşimi (2,11,20 ve 29. maddeler), Açık (net) Hedefler (3,12,21 ve 30. maddeler), Belirli Geri Bildirim (4,13,22,31 maddeler), Göreve Odaklanma (5,14,23 ve 32. maddeler), Kontrol Duygusu (6,15,24 ve 33. maddeler), Kendilik Farkındalığının Azalması (7,16,25 ve 34. maddeler), Zamanın Dönüşümü (8,17,26 ve 35 . maddeler), Amaca Ulaşma Deneyimi'dir (9,18,27 ve 36. maddeler). Ölçekte yer alan her madde "Hiçbir Zaman (1)" ile "Her Zaman (5)" arasında değişen 5'li Likert ölçek üzerinde cevaplandırılmaktadır.

\section{İstatistiksel işlemler:}

Verilerin analizinde 23.00 SPSS paket programı kullanılmıştır. Ölçek sonucu elde edilen veriler puanlama yönergesine uygun olarak hesaplanmıştır. Veriler değerlendirilirken "Kolmogorov Smirnov Testi” ile normal dağılıma uygunluğu araştırılmış ve tüm verilerin normal dağılıma uyduğu tespit edilmiştir. Karşılaştırmalarda t- testi kullanılmıştır.

Tablo 1: Araştırmaya Katılan Öğrencilerin Yaş, Boy uzunluğu ve Vücut Ağırlığı Değerleri $(\mathrm{n}=190)$

\begin{tabular}{cllll}
\hline & Ortalama & St. sapma & Minimum & Maksimum \\
\hline Yaş (Yıl) & 22,13 & 1,90 & 19 & 26 \\
\hline Boy uzunluğu $(\mathrm{cm})$ & 171,90 & 14,72 & 166 & 191 \\
\hline Vücut ağırlığı $(\mathrm{kg})$ & 68,89 & 10,86 & 47 & 98 \\
\hline
\end{tabular}


Tablo 2: Cinsiyete Göre Optimal Performans Duygu Durum Ölçeği Alt Boyutları Karşılaştırılması

\begin{tabular}{|c|c|c|c|c|c|}
\hline & Cinsiyet & $\mathrm{N}$ & Ortalama & St. sapma & t-test \\
\hline \multirow{2}{*}{$\begin{array}{l}\text { Görev zorluğu/Beceri } \\
\text { dengesi }\end{array}$} & Erkek & 108 & 16,80 & 2,04 & \multirow[t]{2}{*}{$-1,10$} \\
\hline & Kadın & 82 & 17,21 & 2,93 & \\
\hline \multirow[t]{2}{*}{ Eylem farkındalık birleşimi } & Erkek & 108 & 16,61 & 2,47 & \multirow[t]{2}{*}{$-0,88$} \\
\hline & Kadın & 82 & 17,03 & 2,17 & \\
\hline \multirow[t]{2}{*}{ Açık hedefler } & Erkek & 108 & 16,77 & 2,34 & \multirow[t]{2}{*}{$-1,58$} \\
\hline & Kadın & 82 & 17,41 & 2,11 & \\
\hline \multirow[t]{2}{*}{ Belirli geri bildirim } & Erkek & 108 & 16,97 & 2,15 & \multirow[t]{2}{*}{$-0,13$} \\
\hline & Kadın & 82 & 16,96 & 2,05 & \\
\hline \multirow[t]{2}{*}{ Göreve odaklanma } & Erkek & 108 & 16,72 & 2,24 & \multirow[t]{2}{*}{$-0,59$} \\
\hline & Kadın & 82 & 16,89 & 2,30 & \\
\hline \multirow[t]{2}{*}{ Kontrol duygusu } & Erkek & 108 & 16,95 & 2,15 & \multirow[t]{2}{*}{0,25} \\
\hline & Kadın & 82 & 16,89 & 2,59 & \\
\hline \multirow{2}{*}{$\begin{array}{l}\text { Kendi farkındalığını } \\
\text { Azalması }\end{array}$} & Erkek & 108 & 16,19 & 3,32 & \multirow[t]{2}{*}{$-0,73$} \\
\hline & Kadın & 82 & 16,64 & 3,11 & \\
\hline \multirow[t]{2}{*}{ Zamanın dönüşümü } & Erkek & 108 & 16,43 & 2,37 & \multirow[t]{2}{*}{$-1,61$} \\
\hline & Kadın & 82 & 17,19 & 2,04 & \\
\hline \multirow[t]{2}{*}{ Amaca ulaşma deneyimi } & Erkek & 108 & 17,36 & 1,89 & \multirow[t]{2}{*}{$-0,93$} \\
\hline & Kadın & 82 & 17,58 & 1,86 & \\
\hline
\end{tabular}

Tablo 3: Takım Ve Ferdi Spor Yapma Durumuna Göre Optimal Performans Duygu Durum Ölçeği Alt Boyutları Karşılaştırılması

\begin{tabular}{|c|c|c|c|c|c|}
\hline & & & Ortalama & St. sapma & t-test \\
\hline \multirow{2}{*}{$\begin{array}{l}\text { Görev zorluğu/Beceri } \\
\text { dengesi }\end{array}$} & Takım sporu & 104 & 16,87 & 2,05 & \multirow[t]{2}{*}{$-0,42$} \\
\hline & Ferdi spor & 86 & 17,06 & 1,93 & \\
\hline \multirow{2}{*}{$\begin{array}{l}\text { Eylem farkındalık } \\
\text { birleşimi }\end{array}$} & Takım sporu & 104 & 16,52 & 2,37 & \multirow[t]{2}{*}{$-1,43$} \\
\hline & Ferdi spor & 86 & 17,17 & 2,33 & \\
\hline \multirow[t]{2}{*}{ Açık hedefler } & Takım sporu & 104 & 17,04 & 2,33 & \multirow[t]{2}{*}{0,23} \\
\hline & Ferdi spor & 86 & 16,93 & 2,20 & \\
\hline \multirow[t]{2}{*}{ Belirli geri bildirim } & Takım sporu & 104 & 16,84 & 2,22 & \multirow[t]{2}{*}{$-0,98$} \\
\hline & Ferdi spor & 86 & 17,19 & 1,90 & \\
\hline \multirow[t]{2}{*}{ Göreve odaklanma } & Takım sporu & 104 & 16,65 & 2,25 & \multirow[t]{2}{*}{$-0,75$} \\
\hline & Ferdi spor & 86 & 17,01 & 2,27 & \\
\hline \multirow[t]{2}{*}{ Kontrol duygusu } & Takım sporu & 104 & 16,89 & 2,30 & \multirow[t]{2}{*}{$-0,42$} \\
\hline & Ferdi spor & 86 & 17,01 & 2,32 & \\
\hline \multirow{2}{*}{$\begin{array}{l}\text { Kendi farkındalığını } \\
\text { Azalması }\end{array}$} & Takım sporu & 104 & 16,26 & 3,12 & \multirow[t]{2}{*}{$-0,36$} \\
\hline & Ferdi spor & 86 & 16,49 & 3,49 & \\
\hline \multirow[t]{2}{*}{ Zamanın dönüşümü } & Takım sporu & 104 & 16,44 & 2,35 & \multirow[t]{2}{*}{$-1,64$} \\
\hline & Ferdi spor & 86 & 17,14 & 2,10 & \\
\hline \multirow[t]{2}{*}{ Amaca ulaşma deneyimi } & Takım sporu & 104 & 17,36 & 1,96 & \multirow[t]{2}{*}{$-0,58$} \\
\hline & Ferdi spor & 86 & 17,57 & 1,74 & \\
\hline
\end{tabular}

\section{Tartışma ve Sonuç}

Araştırmaya katılan üniversite spor eğitimli öğrencilerin ortalama olarak yaşları 22,13 yıl, boy uzunlukları 171,90 cm ve vücut ağırlıkları $68,89 \mathrm{~kg}$ olarak bulunmuştur.

Tek bir aktivite sırasında bütün dokuz bileșenin (Görev zorluğu/Beceri dengesi, Eylem farkındalık birleşimi, Açık hedefler, Belirli geri bildirim, Göreve odaklanma, Kontrol duygusu, 
Kendi farkındalığını Azalması, Zamanın dönüşümü ve Amaca ulaşma deneyimi) optimize edilmesi optimal uyarılma durumu oluşturabileceği fikrinden yola çıkan optimal performans duygu durumu kuramı performansın olumlu şekilde etkilenebileceğini vurgular (Yıldız ve ark.,2015). Yıldız ve ark., (2015) çalışmasında optimal performans duygu durumlarının cinsiyet faktörü ile farklılık gösterdiği saptanmıştır. Bu farklılık sonucunda erkek sporcuların kadın sporculara oranla daha yüksek puan ortalamalarına sahip oldukları belirtilmiştir. Ersöz (2011) tarafından yapılan araştırmaların bulguları da benzerdir. Bayköse (2014) tarafından yapılan araştırmada da yalnızca optimal performans duygu durumunun alt boyutu olan Kendilik Farkındalığının Azalması alt boyutunda farklılık vardır. Sharp ve ark., (2007) ise yapmış oldukları çalışma sonucunda, optimal performans duygu durumunun fiziksel aktivite türüne ve cinsiyete göre değişkenlik göstermediğini belirtmişlerdir. Murcia ve ark., (2008) farklı branşlarda yer alan sporcuların optimal performans duygu durumlarını cinsiyete göre değerlendirmişler, erkek ve kadın sporcuların performans duygu durumları arasında bir fark olmadığını ortaya koymuşlardır. Koehn (2007) tarafından elde edilen sonuçlar da cinsiyet farkı olmadığı belirtilmiştir. Bu çalışmada cinsiyete göre optimal performans duygu durum ölçeği alt boyutları karşılaştırılmasında alt boyutlarda anlamlı bir farklılık bulunmamıştır $(\mathrm{p}>0,05)$. Kadın ve erkek öğrenci sporcuların performans duygu durumlarının benzer olduğu söylenebilir. Yine ölçekten her alt boyut için en yüksek 20 puan alınabilir. Bu çalışmada ortalamalara bakıldığında tüm alt boyut puan ortalamaları 20 puana yakındır. Bu nedenle çalışmaya katılan spor eğitimi alan öğrencilerin optimal performans duygu durumları iyi olarak kabul edilebilir.

Seleciler (2019) yaptığı çalışmada Katılımcı öğrencilerin cinsiyet değişkenini ile optimal performans duygu durumu ölçeği alt boyutlarının ortalama puanları arasında istatistiksel anlamda farklılık bulmamıştır. Russell (2001), 42 sporcu üzerinde cinsiyete göre optimal performans duygu durumlarında bir fark bulamazken, takım sporları ile uğraşan sporcuların eylem farkındalık birleşimi alt boyutu puanlarının bireysel sporla uğraşan sporcuların puanlarından daha yüksek olduğunu tespit etmiştir. Altıntaş ve ark., (2010) yaptıkları bir çalışmada erkek ve kadın egzersiz katılımcılarının yapmış oldukları fiziksel etkinliği başarabilme algılarının benzer olduğunu; her iki grubun da hareketleri otomatik olarak düşünmeden yapabildiği hissine sahip olduklarını, etkinliğe odaklanarak, yaptıkları etkinliklerden benzer düzeyde içsel haz aldıklarını göstermektedir. $\mathrm{Bu}$ çalışmada takım ve ferdi spor yapmaya göre optimal performans duygu durum ölçeği alt boyutları karşılaştırılmasında alt boyutlarda anlamlı bir farklılık bulunmamıştır $(\mathrm{p}>0,05)$. Öğrencilerin benzer eğitim almalarının da bu duruma katkısı olabilir. Çünkü Sarı ve Külle (2018) yaptıkları bir çalışmada Optimal performans duygu durumuna en çok katkı sağlayan antrenör davranışının ise pozitif geri bildirim davranışı olduğu belirlenmiştir. Bu nedenle sporcuların antrenman içerisinde ve dışarısında yaptığı olumlu davranışlarda takdir edilmesi gerektiği ve sporculara olumlu geri bildirimlerde bulunulmasının optimal performans duygu durumları açısından önemli olduğu belirtilmiştir. Sarı ve Deryahanoğlu (2019) yapmış oldukları araştırmlarında da antrenörlerin sporcuların ahlaktan uzaklaşmasına, performanslarına önemli bir etki ettiklerini belirtmişlerdir.

Sonuç: Üniversite de Spor Eğitimi alan öğrencilerin Optimal performans duygu durumu iyi olarak kabul edilebilir. Optimal performans duygu durumu puanları cinsiyete, takım ve ferdi spor yapma durumuna göre benzer olduğu tespit edilmiştir. Farklı yaş kategorilerinde ve farklı gruplarda (elit sporcu, engelli sporcular) optimal performans duygu durumunun hangi alt boyutlarda farklılaştı̆̆ incelenmelidir.

\section{Kaynakça}

Ada E.N.D., Aş̧̧ı H., Çetinkalp F.Z.K. Altıparmak M. E. (2012). Sürekli Optimal Performans Duygu Durum-2 (SOPDD-2) Ölçeğinin Beden Eğitimi Dersi İçin Değerlendirilmesi, Hacettepe J. of Sport Sciences, 23 (2), 43-49 
Altıntaş, A., Aşçi F.H., Çağlar E. (2010). Sürekli Optimal Performans Duygu Durumu Ve Egzersiz Davranış1, Hacettepe J. of Sport Sciences, 21 (2), 71-78.

Asakawa K. (2004). Flow experience and autotelic personality in Japanese college students: How do they experience challenges in daily life? Journal of Happiness Studies, 5, 123-154.

Aşçı FH, Çağlar E, Eklund RC, Altıntaş A, Jackson S. (2007). Durumluk ve sürekli optimal performans duygu durum-2 ölçeklerinin uyarlama çalışması. Hacettepe Spor Bilimleri Dergisi, 18 (4), 182-196.

Bayköse N. (2014). Sporcularda kendinle konuşma ve imgeleme düzeyinin optimal performans duygu durumunu belirlemedeki rolü, Selçuk Üniversitesi Beden Eğitimi ve Spor Anabilim Dalı Yüksek Lisans Tezi, http://hdl.handle.net/123456789/7451

Csikszentmihalyi M. (1990). The psychology of optimal experience. (M. Csikszentmihalyi ed.). Newyork: Harper Perennial.

Deci EL, Ryan RM. (1985). Intrinsic Motivation and Self-determination in Human Behavior. New York: Plenum Press.

Ersöz. G., Egzersize Katılım Güdüsü, Sürekli Optimal Performans Duygu Durumu ve Sosyal Fizik Kaygı Düzeyinin Egzersiz Davranış Basamağına ve Fiziksel Aktivite Düzeyine Göre İrdelenmesi, Doktora Tezi, Ege Üniversitesi, Sağlık Bilimleri Enstitüsü, Sporda Psiko Sosyal Alanlar Ana Bilim Dalı, İzmir, 2011

Jackson SA, Kimiecik JC, Ford SK, Marsh HW. (1998). Psychological correlates of flow in sport. Journal of Sport \& Exercise Psychology, 20, 358-378

Koehn. S. (2007). Opensity And Attainment Of Flow State, Victoria University, School Of Human Movement Recreation And Performance, Faculty Of Human Development, Doctorate Thesis

Moneta GB. (2004). The flow experience across cultures. Journal of Happiness Studies, 5, 2, 115 121.

Murcia JAM, Gimeno EC, Coll DGC. (2008). Relationship among goal orientations, motivational climate and flow in adolescents athletes: Differences by gender. The Spanish Journal of Psychology, 11, 1, 181-191.

Russell WD. (2001). An examination of flow state occurrence in college athletes. Journal of Sport Behavior, 24, 1, 83-107.

Sarı İ., Gülle M. (2018). Sporcuların Algıladıkları Antrenör Davranışları ve Optimal Performans Duygu Durumu Arasındaki İlişkinin İncelenmesi, Cemil Meriç - 10. Sosyal Bilimler ve Spor Kongresi Bildiri Tam Metin Kitabı, sh. 210-215

Sarı, İ, Deryahanoğlu, G. (2019). Sporcularda Ahlaktan Uzaklaşmanın Güdüsel İklim Ve Sporcuların Önem Verdikleri Özellikler İle İlişkisi. Spormetre Beden Eğitimi Ve Spor Bilimleri Dergisi, $17 \quad$ (4), 91-104. Retrieved From Https://Dergipark.Org.Tr/Tr/Pub/Spormetre/İssue/50548/536451

Seleciler C. (2019). Halk Dansları Eğitimi Gören Üniversite Öğrencilerinin İmgeleme ve Optimal Performans Duygu Durumu Düzeylerinin Belirlenmesi, Bartın Üniversitesi Eğitim Bilimleri Enstitüsü Beden Eğitimi ve Spor Öğretimi Ana Bilim Dalı Beden Eğitimi ve Spor Eğitimi Bilim Dalı Yüksek Lisans Tezi. 
Sharp EH, Coastsworth JD, Darling N, Cumsille P , Ranieri S. (2007). Gender differences in the self-defining activities and identity experiences of adolescents and emerging adults. Journal of Adolescence, 30, 251-269.

Yıldız B. A., Gülşen D. B. A., Yılmaz B. (2015). Sporcuların Optimal Performans Duygu Durumunun Yaşam Tatminleri Üzerindeki Etkisi, Niğde University Journal of Physical Education And Sport Sciences, 9:55-61. 